Çukurova Üniversitesi Mühendislik Fakültesi Dergisi, 36(1), ss. 25-32, Mart 2021

Cukurova University Journal of the Faculty of Engineering, 36(1), pp. 25-32, March 2021

\title{
Bir Doğaltaş İşleme Fabrikasında Çalışanların Metabolizma Hızları Göz Önüne Alınarak Termal Konfor Şartlarının İncelenmesi
}

\author{
Ali Ekrem ARITAN*1, Zişan MEMiş' \\ ${ }^{1}$ Afyon Kocatepe Üniversitesi, Mühendislik Fakültesi, Maden Mühendisliği Bölümü, \\ Afyonkarahisar
}

Öz

Geliş tarihi: 25.01 .2021

Kabul tarihi: 31.03 .2021

Doğaltaş işleme fabrikalarında çalışanların meslek hastalığına yakalanması durumunu ortam kalitesi etkilemektedir. Ortam kalitesini belirleyen en önemli faktörler; termal konfor şartları, aydınlatma, ortaya çıkan gürültü ve titreşimdir. Termal konforu tanımlayan 6 önemli parametre vardır. Termal konfor şartlarını etkileyen metabolizma hızı, çalışanların işlerinin ağırlığına göre farklılık göstermektedir. Çalışma ortamında sıcaklık, nem vb. etkenler aynı olsa bile çalışanların metabolizma hızındaki farklılık, termal konfor algısını değiştirecek bir etken olarak karşımıza çıkmaktadır. Metabolik oran hem araştırma hem de uygulamada en kabaca değerlendirilen faktördür. Çalışma sahası olarak Afyonkarahisar İl'inde bulunan doğaltaş fabrikası belirlenmiştir. Fabrika içerisinde 6 farklı bölgeden ölçümler alınmıştır. Çalışanların metabolik oranlarının farklı olmasının termal rahatlığı etkilemesi göz önüne alınarak riskli ortamlar için önerilerde bulunulmuştur.

Anahtar Kelimeler: Termal konfor, Metabolik oran, İş sağlığı ve güvenliği

\section{Investigation of Thermal Comfort Conditions by Considering Metabolic Rates of Natural Stone Processing Plant Employees}

\begin{abstract}
The employees in the natural stone factory are exposed to occupational diseases by the quality of the environment. The most important factors determining the quality of the environment are thermal comfort conditions, lighting, the ambient noise and vibration. There are 6 important parameters defining thermal comfort. The metabolic rate, which affects the thermal comfort conditions, varies according to the intensity of the employees' work. Even if the factors such as temperature, humidity etc. are the same in the working environment, the difference in the metabolic rate of the employees appears as a factor that will change the perception of thermal comfort. The metabolic rate is considered the least important in both research and practice. A natural stone factory in Afyonkarahisar Province was chosen as the study area. Measurements were taken from 6 different regions within the factory. Considering that different metabolic rates of employees affect thermal comfort, suggestions have been made for risky environments.
\end{abstract}

Keywords: Thermal comfort, Metabolic rate, Occupational health and safety

*Sorumlu yazar (Corresponding author): Ali Ekrem ARITAN, aritan@aku.edu.tr 


\section{GíRiș}

Madencilik sektörünün ekonomiye katkısı yüksektir. Ülkemizde doğaltaş ihracatı artarak maden sektöründeki önemini devam ettirmektedir. Son yıllarda insanların doğal güzellikleri görme, kullanma talebi artmaktadır ve geleneksel yapılarda, turizm mekânlarında, kendi özel alanlarında doğaltaş kullanmak istemektedirler. Taleplerin karşılanması için doğaltaş ocak ve işleme tesislerindeki çalıșmalar da doğal olarak artmaktadır. Afyonkarahisar, doğaltaş ocaklarının ve tesislerinin en yaygın bulunduğu illerden birisidir. Afyonkarahisar'da 400 civarında mermer işleme tesisi bulunmaktadır. Bu tesisler büyük miktarda istihdam sağlamaktadır.

Ülkemizde bulunan geleneksel yapıların restore edilmesinde, turizm mekânlarında otantik dekorasyon görünümünün sağlanmasında ve yeni yapılan inşaatların yapım aşamalarında doğaltaş kullanımına talep giderek artmaktadır. Talebin karşılanması için üretim ve işleme çalışmaları da artmaktadir.

Üretim ve hammadde işleme çalışmaları yapılırken fiziksel risk etmenleri ortaya çıkmaktadır. Fiziksel risk etmenleri; gürültü, termal konfor, aydınlatma, titreşim, toz, basınç ve radyasyondur. Fabrikada bulunan makinelerde sulu çalışmalar yapıldığı için toz problemi görülmemektedir. Çalışma yapılan makineler de sadece forklift kullanılırken titreşim problemi ortaya çıkmaktadır [1,2]. Üretim ve işleme süreçlerinde makineleşme arttıkça fabrikada ortaya çıkan gürültü artış göstermektedir. Ortaya çıkan gürültü insanlar üzerinde psikolojik, fizyolojik ve işitme duyusunda olumsuz etkiler ortaya çıkarmaktadır [3]. Hayatımızın her anında olan temel gereksinimlerimizden biri 1şıktır. Çalışma ortamlarında herhangi bir eylemi gerçekleştirebilmek için 1 şık yayan, yansıtan ya da geçiren bir nesnenin varlığına ihtiyaç duyulmaktadır [4].

Fabrika içerisindeki hava sıcaklığı, radyant 1s1, hava akım hızı ve nem gibi çevresel faktörlerle birlikte kıyafet faktörü ve metabolizma hızı gibi kişisel faktörlerin etki ettiği termal konfor faktörleri çalışma ortamına göre değişiklik göstermektedir. Bu değişiklikler çalışanlar üzerinde kalp krizine kadar olumsuz etkiler ortaya çıkarabilmektedir [5].

Literatür incelendiğinde, madencilik sektörüne yönelik termal konfor çalışmalarında, genel olarak ortaya çıkan olumsuz faktörler (sıcaklık, hava hızı, nem) incelenmiştir. Fakat doğaltaş işleme fabrikalarında termal konfor incelemeleri yapılmasına rağmen metabolik oranla 1sıl konforun ilişkisi vurgulanmamıştır. Maohui Luo ve arkadaşlarının 2018 yılında yaptıkları çalışmada [6], sürekli metabolizma hızı ölçümünün alınmasının zor olduğu sonucuna varmışlardır.

Çalışma karasal iklime sahip olan Afyonkarahisar ilinde yapılmıștır. 1 Katrak ve 2 ST kullanılan, çalışma alanları yarım duvarla bölünmüş olan doğaltaş işleyen $3500 \mathrm{~m}^{2}$ alana sahip bir kapalı fabrikada; çalışanların metabolik oranlarının farklılık gösterdiği ortamlardan termal konfor ölçümleri alınmıştır. Ölçümler sonucunda, metabolik oran farklılıklarına göre karşılaştırmalar yapılmıştır. Değerlendirmeler sonucunda öneriler ortaya konulmuştur.

\section{FİZIKKSEL RİSK ETMENLERİ}

Çalışanlar için en büyük temel riskler iş kazası ve meslek hastalığıdır. İş kazaları ve meslek hastalıklarına sebep olan en büyük etkenler arasında çalışılan ortam koşullarının olumsuz olması yer almaktadır. Çalıșılan ortamın fiziksel özellikleri çalışanların iş verimini etkilemektedir. Fiziksel etmenleri; termal konfor, aydınlatma, gürültü, titreşim, toz, basınç ve radyasyondur. Termal konfor riskini etkileyen en önemli faktörlerden biri metabolik orandır. Metabolizma hızı farklılık gösteren çalışanların termal rahatlıkları da değişiklik göstermektedir [7].

\subsection{Termal Konfor}

Çalışma ortamları, çalışanların psikolojilerini, bedensel, sosyal ve kültürel yapılarını etkilemeyecek şekilde rahat olması gerekmektedir. Ortamın 1sıl konforunu sağlayacak olan cihaz ve ekipmanlar çalışanları rahatsız etmeyecek şekilde 
seçilmelidir. Çalışma ortamları termal konfor şartlarına uygun tasarımlandırılmalıdır. ASHRAE 55 Standardına uygun olarak çalışılan ortamın isıl konforundan memnun olma durumu, termal konfor olarak adlandırılmaktadır [8]. Termal rahatlık, çalışanın ortamdaki tatminini gösteren önemli bir terimdir. Çalışanın iş randımanını yükselten en önemli faktörlerden biri de termal memnuniyetidir. [8-10].

Termal konfor; hava sıcaklığı (T), bağıl nem (RH), hava hızı (V), ortalama 1şıma sıcaklığı (Tg) gibi çevresel faktörlere bağlıyken kişinin yaşı, cinsiyeti, beslenmesi, metabolizma düzeyi ve kıyafet 1sıl direnci gibi kişisel faktörlere de bağlıdır. Kıyafet 1sıl direnci, çalışan ile çalışma ortamı arasındaki 1sı iletimi için bir etkendir [8,1113].

Termal konfor parametreleri ölçüldüğünde, termal algı tahmini ortalama olarak (PMV) hesaplanmış olur [13]. Hesaplamada Fanger metodu kullanılır. Metoda göre 6 bileşenden 4'ü ölçümle ikisi standartlardan alınarak PMV hesaplaması yapılır [5].

Isıl konfor memnuniyetsizliği, çalışılma yerinde bölgesel soğutma veya çalışanın vücut sıcaklığının artması sebebiyle de oluşabilir. Ayrıca, termal konfor olumsuzluğu, tüm vücudun sicak veya soğuktan rahatsızlığından kaynaklanabilir [13].

Doğaltaş işleme tesislerindeki çalışanların termal rahatlı̆̆ını etkileyen faktörler;

- ST ve Katrak makinelerinin olduğu bölümde, makinelerin çalışma yöntemleri sebebiyle, ortamda su varlığının fazla olması nem sorunu oluşturmaktadır.

- Fabrika içinde yeterince havalandırma olmaması durumu hava hızının ayarlanmasında problemler ortaya çıkarmaktadır.

Metabolizma hızı ve kıyafet faktörü çalışanların termal rahatlığını etkilemektedir. Fabrika içerisinde bulunan çalışma ortamları aynı olmağı için metabolik oranda farklılık göstermektedir.
İnsan vücudunun ürettiği 1s1, metabolizma hız1 olarak isimlendirilir. Vücut 1S1s1, besinlerin yakılması ile meydana gelen enerji sonucu elde edilir. Çalışanlar faaliyetlerini gerçekleştirirken vücutlarının aldığı şekillerin metabolizma hızına ve üretilen sıcaklığa etkisi fazladır. Aynı işi yapan çalışanların 1sı değerleri farklı olarak ortaya çıkmaktadır. Bu farklılığı azaltmak için birim vücut yüzey alanına bağlı değişkenler kullanılmaktadır [8].

Metabolik oran, metabolik aktivite nedeniyle vücudun içinde üretilen enerjiyi karakterize eder.

$* 1 \mathrm{Met}=58,2 \mathrm{~W} / \mathrm{m}^{2}\left(18,4 \mathrm{BTU} / \mathrm{H} \mathrm{FT}^{2}\right)$.

Bazı çalışma durumlarındaki metabolik hızlar Çizelge 1'de verilmiştir.

Çizelge 1. Metabolik oranların aktiviteye göre siniflandirılmasi [14,15]

\begin{tabular}{|l|c|l|}
\hline Sınıfı & $\begin{array}{c}\text { Ortalama } \\
\text { metabolik hız } \\
\left(\mathrm{W} \mathrm{m}^{-2}\right)\end{array}$ & Örnek \\
\hline Dinlenme & 65 & Dinlenme \\
\hline Düşük & 100 & Rahat oturma/ayakta \\
\hline Orta & 165 & $\begin{array}{l}\text { Sürekli el/kol } \\
\text { çalışması }\end{array}$ \\
\hline Yüksek & 230 & Yoğun çalışma \\
\hline $\begin{array}{l}\text { Çok } \\
\text { yüksek }\end{array}$ & 290 & $\begin{array}{l}\text { Maksimum aktivite } \\
\text { için çok yoğun }\end{array}$ \\
\hline
\end{tabular}

Çizelge 2. Fabrika çalışanlarının metabolik eşdeğer dakika (MET) hesaplanması

\begin{tabular}{|c|c|c|c|}
\hline Bölge & Sınıfı & $\begin{array}{c}\text { Ortalama } \\
\text { Metabolik } \\
\text { Hızı }\left(\mathrm{W} / \mathrm{m}^{2}\right)\end{array}$ & $\begin{array}{c}\text { MET } \\
\text { değeri }\end{array}$ \\
\hline 1. Bölge & Düşük & 100 & 1,72 \\
\hline 2. Bölge & Yüksek & 230 & 3,95 \\
\hline 3. Bölge & Yüksek & 230 & 3,95 \\
\hline 4. Bölge & Düşük & 100 & 1,72 \\
\hline 5. Bölge & Düşük & 100 & 1,72 \\
\hline 6. Bölge & Düşük & 100 & 1,72 \\
\hline
\end{tabular}

Metabolik oranların aktiviteye göre sınıflandırılması (ISO 8996, 2004) Çizelge 1'e bakılarak, ölçüm alınan ortamdaki çalışanların sınıfı belirlenmiştir. Ortalama metabolik hızından $1 \mathrm{Met}=58,2 \mathrm{~W} / \mathrm{m}^{2}$ (18.4 BTU / $\left.\mathrm{H} \mathrm{FT}^{2}\right)$ formülü kullanılarak Met değerleri bulunmuştur (Çizelge 2). 
İnsan vücudu ile dış ortamı ayıran giysinin, 1sı ve nem transferi çok önemlidir. Isıl konforun tanımlanmasında, giysilerin 1sı transferine karş1 direnci, kıyafetin cinsine göre aldığı yalıtım birimi ile ifade edilmektedir [8].

Çizelge 3. Çeşitli giysi türleri ve yalıtım katsayıları [5,8]

\begin{tabular}{|l|c|}
\hline Kiyafet Yalıtım Katsayısı & $\mathrm{I}_{\mathrm{c}_{1}}$ (clo) değeri \\
\hline $\begin{array}{l}\text { Pantolon, kısa kollu } \\
\text { gömlek }\end{array}$ & 0,57 \\
\hline $\begin{array}{l}\text { Pantolon, uzun kollu } \\
\text { gömlek }\end{array}$ & 0,61 \\
\hline $\begin{array}{l}\text { Pantolon, uzun kollu } \\
\text { gömlek, ceket }\end{array}$ & 0,96 \\
\hline $\begin{array}{l}\text { Diz uzunluğunda etek, } \\
\text { kısa kollu gömlek }\end{array}$ & 0,54 \\
\hline $\begin{array}{l}\text { Ayak bileği uzunluğunda } \\
\text { etek, uzun kollu gömlek, } \\
\text { ceket }\end{array}$ & 1,10 \\
\hline Etek / Elbise & $0,54-1,10$ \\
\hline Şort & 0,36 \\
\hline Önlük / Tulum & $0,72-1,37$ \\
\hline Spor Kiyafetleri & 0,74 \\
\hline
\end{tabular}

Çizelge 3'de belirtilen değerleri; fabrika içerisinde farklı bölgelerde çalışanların kıyafetlerine göre, $\mathrm{I}_{\mathrm{c}_{1}}$ (clo) değerleri belirlenip Çizelge 4'te verilmiştir. Termal konfor koşulları ve metabolik oranları farklı olduğu için ceketlerin farklı kullanılması önerilmiştir.

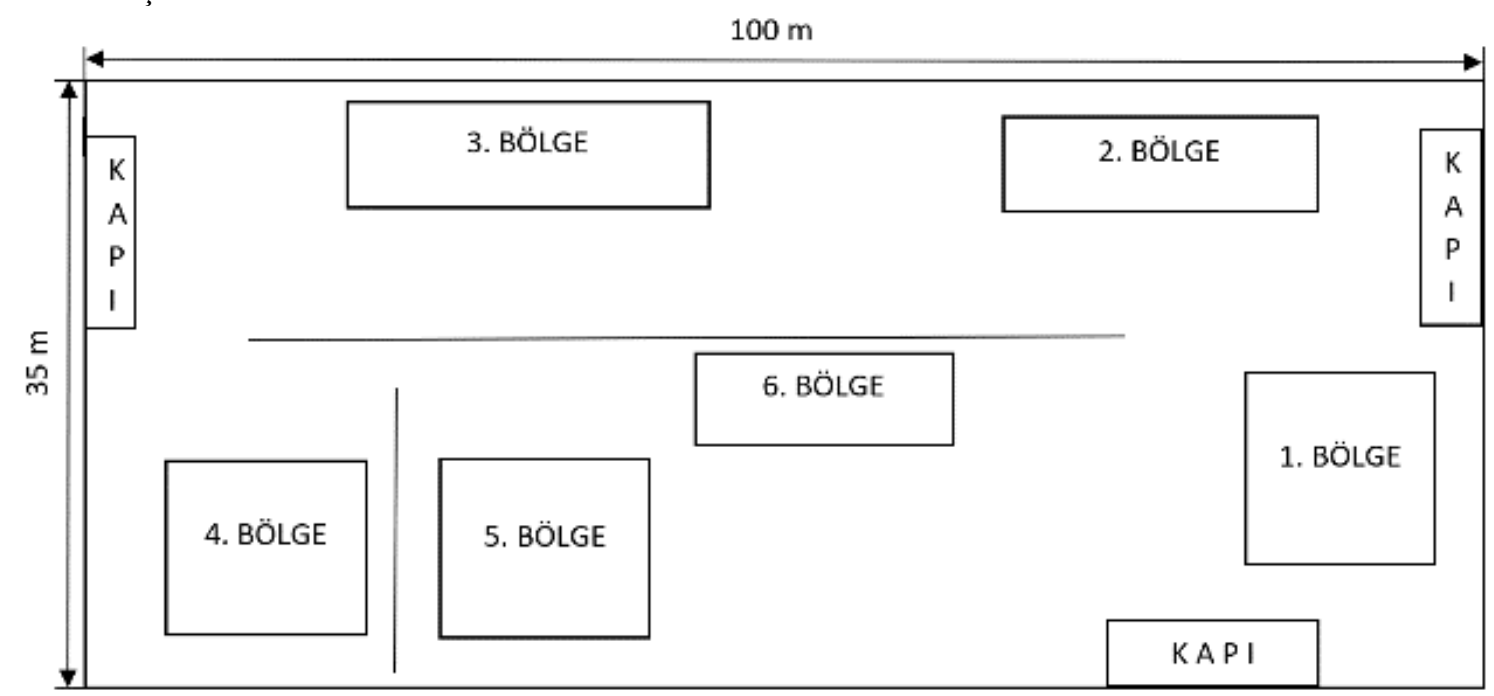

Şekil 1. Ölçeklendirilmemiş fabrika planı
Çizelge 4. Fabrika çalışanlarının I_(c_1)(clo) değerlerinin belirlenmesi

\begin{tabular}{|l|l|c|}
\hline Bölge & Giyim Açıklaması & $\begin{array}{c}\boldsymbol{I}_{\boldsymbol{c}_{\boldsymbol{l}}}(\mathbf{c l o}) \\
\mathbf{d e g ̆ e r i}\end{array}$ \\
\hline 1. Bölge & $\begin{array}{l}\text { Pantolon, uzun } \\
\text { kollu gömlek, ceket }\end{array}$ & 0,96 \\
\hline 2. Bölge & $\begin{array}{l}\text { Pantolon, uzun } \\
\text { kollu gömlek, ceket }\end{array}$ & 0,96 \\
\hline 3. Bölge & $\begin{array}{l}\text { Pantolon, uzun } \\
\text { kollu gömlek, ceket }\end{array}$ & 0,96 \\
\hline 4. Bölge & $\begin{array}{l}\text { Pantolon, uzun } \\
\text { kollu gömlek, ceket }\end{array}$ & 0,96 \\
\hline 5. Bölge & $\begin{array}{l}\text { Pantolon, uzun } \\
\text { kollu gömlek, ceket }\end{array}$ & 0,96 \\
\hline 6. Bölge & $\begin{array}{l}\text { Pantolon, uzun } \\
\text { kollu gömlek, ceket }\end{array}$ & 0,96 \\
\hline
\end{tabular}

\section{MATERYAL VE METOT}

Çalışma 2020 yılında, Afyonkarahisar İli İscehisar İlçesi sınırları içinde bulunan bir doğaltaş fabrikasının 6 farklı bölgesinden termal konfor ölçümleri alınarak yapılmıştır (Şekil 1). Çalışma koşulları farklı olan bu bölgelerde çalışanların metabolizma hızı farklılık göstermektedir. Termal rahatlık; her koşul için değişen metabolik oranla hesaplamalar yapılarak değerlendirilmiştir. Ölçüm yapılan günde, diş ortam şartları; hava sıcaklığı $10,2^{\circ} \mathrm{C}$ iken hava hız $0,9 \mathrm{~km} / \mathrm{s}$ ve nem $\% 56$ ' dır. 


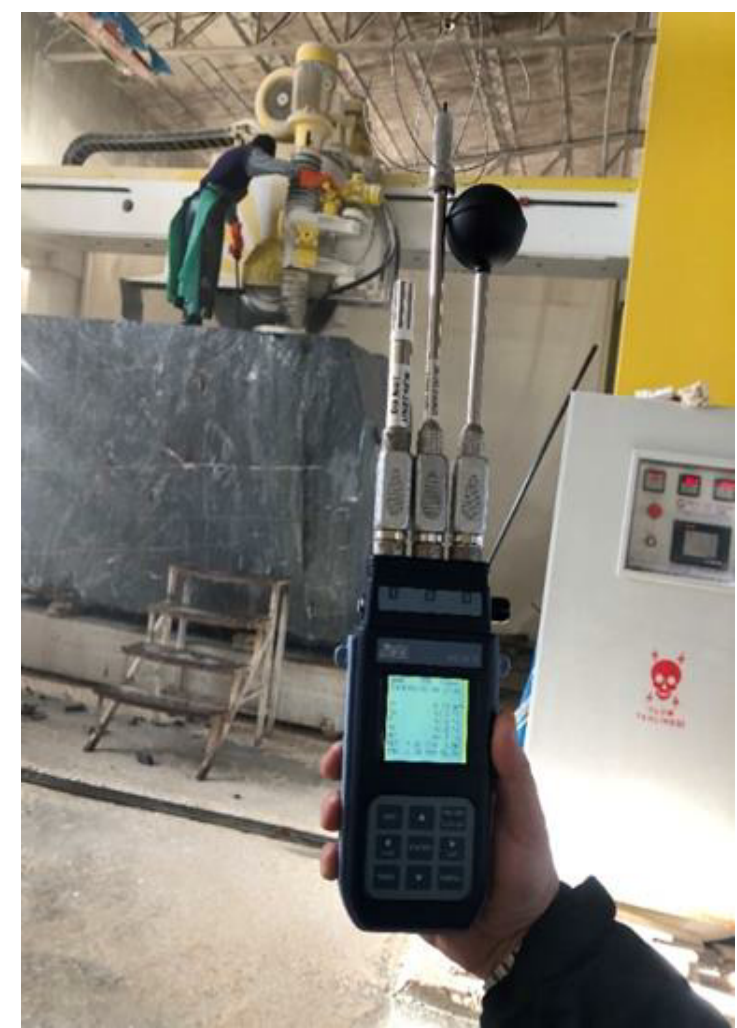

Şekil 2. Termal konfor ölçüm cihazı

Katrak, ST ve köprülü kesme makinesini kullanarak sulu kesim yapılan doğaltaş işleme fabrikasında TS EN 27243, TS EN ISO 7730 standartlarına göre DELTA OHM WBGT 32.3 cihazı ile (Şekil 2) termal konfor ölçümleri alınmıştır $[8,13,16]$. PMV hesaplamasında kullanılan değerler ASHRAE 55'den alınmıştır. Ölçüm sonuçları Fanger modeline göre değerlendirilmiştir [5].

\section{SONUÇLAR}

Alınan termal konfor ölçümlerinde 6 bölgede çalışanların metabolik oranları tek tek ele incelenmiştir. Epoksi çalışmalarının olduğu bölgede fırçalama yaparak, el işi gerektiği ve ebatlama bölgesinde elle yükleme yapıldığ hareketli çalışma yapılmaktadır. Hareket halinde olan işçinin orta metabolizma hızına sahip olmasından dolayı metabolik oran değeri 3,95 met değerindedir. Çalışma yapılan ortamların sıcaklığının düşük olmasına rağmen metabolik oranlarının yüksek olması, çalışanların 1. ve 3 . bölgede hissettiği termal rahatlığın uygun olduğunu göstermektedir (Şekil 3 ve 4).

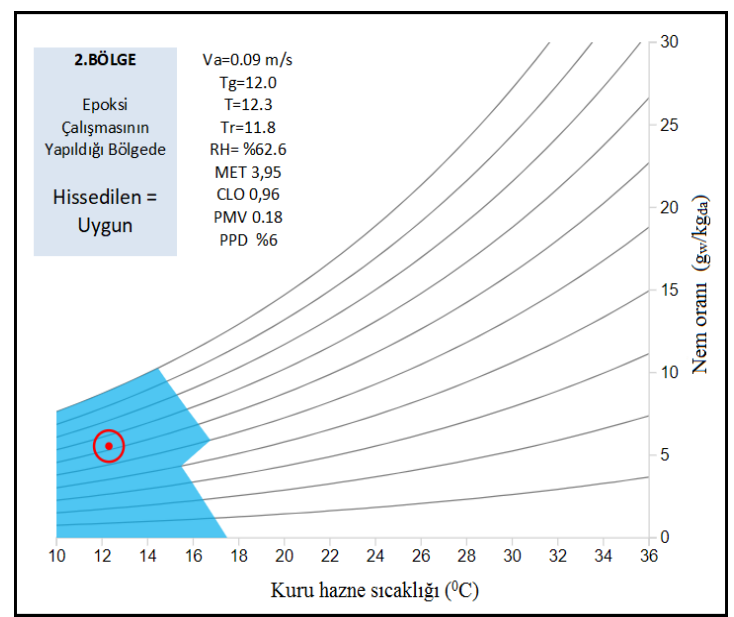

Şekil 3. İkinci bölge termal konfor şartları

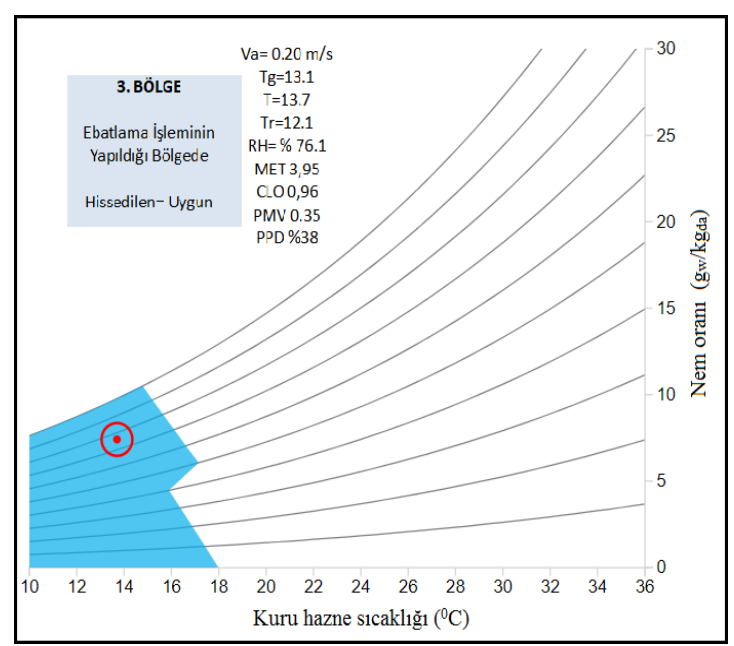

Şekil 4. Üçüncü bölge termal konfor şartları

1., 4., 5. ve 6. bölgelerde ise hareketsiz çalışma şartlarından dolayı çalışanların metabolizma hızları düşüktür. Çalışma ortamlarında, hava sıcaklığının düşük ve çalışanların metabolik oranları da 1,72 met değerinde olması sebebiyle hissedilen termal rahatlığın (Çizelge 5'de görüldüğü üzere PMV değerleri -1,37 ile -1,59 arasında değişmektedir.) serin olduğunu göstermektedir (Şekil 5-8). 
Bir Doğaltaş İşleme Fabrikasında Çalışanların Metabolizma Hızları Göz Önüne Alınarak Termal Konfor Şartlarının Incelenmesi

Çizelge 5. 6 farklı bölgenin PMV değerleri

\begin{tabular}{|c|c|c|}
\hline Bölge & Sinıfı & PMV değeri \\
\hline 1. Bölge & Düşük & $-1,57$ \\
\hline 2. Bölge & Yüksek & 0,18 \\
\hline 3. Bölge & Yüksek & 0,35 \\
\hline 4. Bölge & Orta & $-1,37$ \\
\hline 5. Bölge & Orta & $-1,39$ \\
\hline 6. Bölge & Orta & $-1,39$ \\
\hline
\end{tabular}

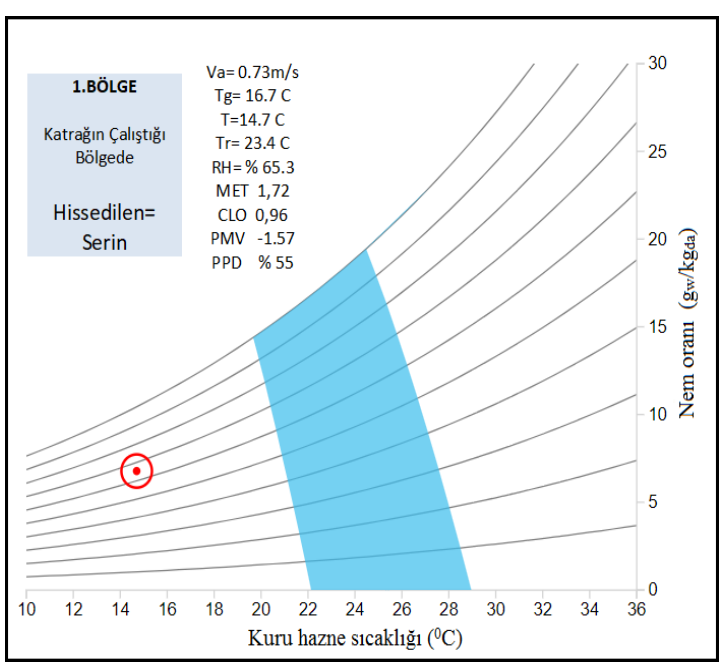

Şekil 5. Birinci bölge termal konfor şartları

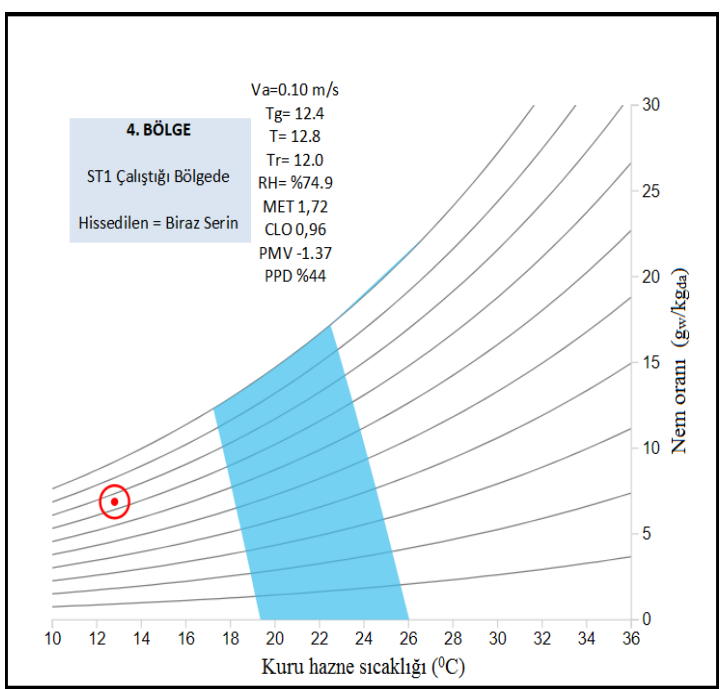

Şekil 6. Dördüncü bölge termal konfor şartları

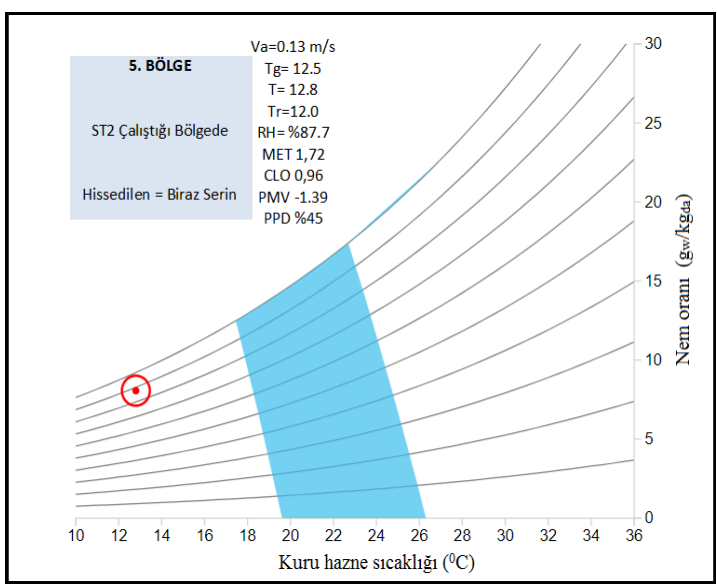

Şekil 7. Beşinci bölge termal konfor şartları

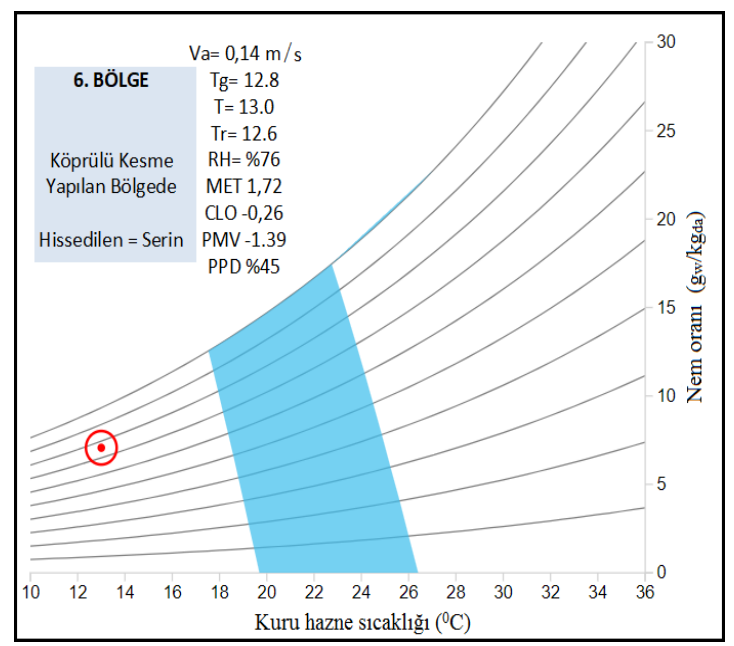

Şekil 8. Altıncı bölge termal konfor şartları

\section{TARTIŞMA VE ÖNERILER}

2017 yılında Arıtan ve arkadaşları tarafından yapılan çalışmada, Afyonkarahisar'daki bazı doğaltaş işleme tesislerinde termal konfor incelemeleri yapmışlardır [15]. Bu çalışmada termal konforun 6 bileşeni dikkate alınmış fakat metabolizma hızı fabrika genelinde sabit alınmıştır. Ayrıca çalışma alanı ve çalışma yapılan bölge sayısı bu yayında 4 bölge ve $2000 \mathrm{~m}^{2}$ 'dir.

Metabolik oranın dikkate alındığı bu çalışmada mevsim şartlarının daha soğuk olduğu zamanda, daha büyük alana sahip (6 bölge, $3500 \mathrm{~m}^{2}$ kapalı 
alan), sulu çalışan makinelerin (ST, Katrak, Köprülü kesme) fazla olmasıyla farklı ortam şartlarına sahip olan bir fabrikadan termal konfor ölçümleri alınmıştır. Alınan ölçümler çalışanların metabolizma hızlarına göre değerlendirilmiştir. Ölçüm alınan ortamda sulu çalışan makine sayısının fazla ve 6 bölgenin ortak etkileşiminin olmasıyla ortaya çıkan nem fazladır. Bu durum çalışanın hissettiği sıcaklığı düşürmekte ve termal rahatlığı bozmaktadır.

Genel olarak bakıldığında; fabrikalarda çalışanların giysileri tek tip olduğu bilinmektedir. Buradan çıkan sonuca göre; aynı fabrika içinde çalışanların termal hissiyatlarında etkin olan faktör metabolik oranlarıdır. Ölçülen 4 bileşende (ortam sıcaklığ1, radyant 1 s1, nem, hava hızı) ve giysi faktöründe değişiklik yaparken metabolizma hızını dikkate alan düzenlemeleri yapmak daha uygun olacaktır. Bu yönüyle bakıldığında metabolik oranın tespitinin doğru yapılmasının önemi daha fazla ortaya çıkmaktadır. Ortamın termal konfor farklılığ 1 düşünüldüğünde, tüm bölgelerde (6 farklı bölgede) çalışanların aynı kıyafet giymeleri uygun olmadığ 1 görülmektedir. 2. ve 3. bölgede çalışanlar şu anki kıyafetlerini giymeye devam ederken; 1. 4. 5 . ve 6 . bölge çalışanlarının vücudunun oluşturduğu 1sıyı koruyan elastik termal yalıtım sağlayan kıyafetler tercih etmeleri gerekmektedir.

Termal konfor ölçüm sonuçlarına bakıldığı zaman bölgelerde hissedilen termal rahatlı̆̆ın metabolik oranla değiştiği görülmüştür. $1,4,5$ ve 6 . bölgelerde metabolik oranın düşük olmasıyla termal hissiyatın serin, termal memnuniyetin düşük olduğu görülmüştür. Çalışılan ortamlardan memnun olunmaması iş randımanını düşürüp çalışanların sağlığında büyük risk göstereceği için kıyafet faktörünün değiştirilmesi önerisi uygun olacaktır ama bu yeterli olmamaktadır. Kiyafet değişikliğinin yanı sıra; termal rahatlığın uygun olmadığ kalori düzenlemesi yaparak metabolik hızlarına göre ayarlanması gerekmektedir.

Termal konfor çalışmaları yapılırken, metabolizma hızını tahminlerini doğrulamak için metabolik oranı etkileyen kalp atışı gibi faktörlere bakılarak yöntemler geliştirilmesi gerektiğini söylemişlerdir.
Çalışma sonucunda düşük maliyetli metabolik oran ölçmek, doğru sonuç verip kullanması kolay olan cihazlara sahip olunmasının termal rahatlık için büyük bir değer olacağı belirtilmiştir [6].

Çalışma saatleri içerisinde, çalışanların metabolik hızının değişiklik gösterdiği zaman dilimlerinde, uygun metabolik oranlar kullanılarak termal konfor ölçümleri değerlendirilmelidir. Bu zaman dilimleri için ortalama metabolik hız belirlenerek ortamda termal konfor düzenlemeleri yapılmalıdır.

Fabrika içerisinde lokal havalandırmalar yapılmalıdır. Hava akış yönüne göre giriş kapılarının belirlenmesi ve nem ortaya çıkaran makinelerin giriş kapılarına yakın konulması gerekmektedir. Böylece ortaya çıkardıkları nemin çalışanlara etkisi azaltılmış olacaktır.

Nem ortaya çıkaran makineler izolasyon tenteleri konularak diğer bölümlerden ayrılmalıdır. Bölümler arasında oluşacak etkileşimin engellenmesi sağlanmalıdır.

Katrak, ST ve köprülü kesme işlemlerinin yapıldığı bölgelerde çalışanların beklemesi ve ortam şartlarından etkilenmemesi için kesme işleminin yapıldığ 1 yere bekleme kabinleri konulup, işçilerin termal rahatlıkları uygun seviyeye getirilmelidir.

\section{KAYNAKLAR}

1. Akbulut, T., 1996. İşçi Sağlığı Prensip ve Uygulamalar1, 5. Bask1, Sistem Yayıncılı, İstanbul, 334.

2. Arıtan, A.E., Tümer, M., Şensöğüt, C., 2016. Kırmataş Sektöründe Titreşim Problemine Genel Bakış, 8. Uluslarası Kırmataş Sempozyumu, Kütahya.

3. Ege, F., Sümer, S.K., Sabanc1 A., 2003. Tekstil Fabrikalarında Gürültü Düzeyi ve Etkileri, Türk Tabipleri Birliği Mesleki Sağlik ve Güvenlik Dergisi, 30-39.

4. MEB, 2011. Aydinlatma Projeleri (522EE0075), Ankara.

5. İmanc1, C., 2014. Döküm Atölyelerinde Termal Konfor Şartlarının İncelenmesi, Uzmanlık 
Tezi, Çalışma ve Sosyal Güvenlik Bakanlığı İş Sağlığı ve Güvenliği Genel Müdürlüğü, 96.

6. Luo, M., Wang, Z., Ke Z., Cao B., Zhai Y., Zhou X., 2018. Human Metabolic Rate and Thermal Comfort in Buildings: The Problem and Challenge, Building and Environment, 131, 44-52.

7. Dülger, S., 2015. Bir Mermer İşletmesindeki Problemlerin TRIZ Yöntemi ile Değerlendirilmesi, Yüksek Lisans Tezi, Eskişehir Osmangazi Üniversitesi Fen Bilimleri Enstitüsü, 112.

8. ASHRAE, ANSI/ASHRAE Standard 55, 2010. Thermal Environmental Conditions for Human Occupancy, ASHRAE Publications.

9. 28710 Sayılı Resmî Gazete, 2013. İşyeri Bina ve Eklentilerinde Alınacak Sağlık ve Güvenlik Önlemlerine İlişkin Yönetmelik, Ankara.

10. Parsons, K.C., 2005. Human Thermal Environments, Taylor \& Francis, New York.

11. Hensen, J.L.M., 1990. Literature Review on Thermal Comfort in Transient Conditions, Building and Environment, 25(4), 309-316.

12. Atılgan, I., Ataer, E., 2009. Application of Thermal Comfort Analysis, IX. HVAC and Sanitary Engineering National Congress, İstanbul.

13. TS EN ISO 7730 Nisan 2006. Orta Dereceli Termal Ortamlar-PMV ve PPD İndislerinin Tayini Termal Rahatlık için Şartların Belirlenmesi. Türk Standartları Enstitüsü, Ankara.

14. ISO 8996 2004. Ergonomics of the Thermal Environment-Determination of Metabolic Rate. International Organization for Standardization, Cenevre.

15. Arıtan, A.E., Tümer, M., Şensöğüt, C., 2017. Doğaltaş Fabrikalarında Maruz Kalınan Fiziksel Risk Etmenleri, Uluslararası Maden İşletmelerinde İşçi Sağlığı ve İş Güvenliği Sempozyumu, Adana.

16. TS EN 27243 Nisan 2002. Sicak Ortamlar WBGT (Yaş-Hazne Küre Sicaklığı) İndeksine Göre Isının Çalışan Üzerindeki Baskısının Tahmini, Türk Standartları Enstitüsü, Ankara. 